\title{
Should cryoballoon ablation of paroxysmal atrial fibrillation be proposed as a first-line treatment?
}

\author{
Alexis Hermida ${ }^{1}$ (D) . Jean-Sylvain Hermida ${ }^{2}$ \\ Received: 15 December 2021 / Accepted: 27 January 2022 / Published online: 4 February 2022 \\ (c) The Author(s), under exclusive licence to Springer Science+Business Media, LLC, part of Springer Nature 2022
}

Atrial fibrillation (AF) is the most frequent heart rhythm disorder, affecting 33.5 million people worldwide in 2010. The incidence of AF increased to a greater extent in developed than in developing countries between 1990 and 2010. AF increases the risks of stroke and heart failure and the rates of hospitalization and mortality. The estimated age-adjusted incidence per 100,000 inhabitants is higher for men than for women: 77.5 (95\% CI, 65.2-95.4) versus 59.5 (95\% CI, 49.9-74.9) in 2010 [1].

The first-line treatment of symptomatic paroxysmal AF is based on antiarrhythmic drugs. In accordance with the European Society of Cardiology (ESC) recommendations, percutaneous catheter ablation is reserved for patients with symptomatic episodes despite treatment with antiarrhythmic drugs (class I indication). Several randomized studies have demonstrated its efficacy in this context [2].

Catheter ablation of symptomatic paroxysmal AF in first line is only a class IIa indication [2]. This recommendation resulted from the publication of the RAAFT 1 and 2 and MANTRA PAF studies, which found a high rate of recurrences in the two groups and a worrying number of complications in the ablation group. In addition, the results of the MANTRA PAF study, despite indicating a trend towards lower rates of recurrence with ablation, did not reach statistical significance. It is only by compiling the data from these 3 studies, corresponding to a total of 491 patients, that a meta-analysis showed that catheter ablation appeared to be superior [3]. Three new randomized trials comparing firstline ablation, this time by cryoballoon, with antiarrhythmic drugs, were published in 2021.

Alexis Hermida

a.hermida.jarry@gmail.com

1 Service de Cardiologie, Rythmologie Et Stimulation Cardiaque CHU Amiens-Picardie, 1, rond-point du Professeur Christian Cabrol, 80054 Amiens Cedex, France

2 Service de Cardiologie, Clinique de l'Europe, Amiens, France

\section{Rationale for first-line ablation}

There are many arguments for early treatment of AF. AF is a disease that progresses over time. The rapid occurrence of atrial myocardium conduction disorders and irreversible fibrosis was demonstrated as early as 2002 , in a dog model of $\mathrm{AF}$ and heart failure. It was thus argued that early treatment was desirable to prevent the atrial remodeling associated with AF [4]. In some patients, AF is initially paroxysmal, subsequently becoming persistent over a period of months or years. For example, in the Canadian CARAF registry, including patients recently diagnosed with paroxysmal AF, the percentage of progression to persistent $\mathrm{AF}$ was 8.6\% after 1 year, $24.3 \%$ after 5 years, and $36.3 \%$ after 10 years [5]. The very recent randomized EAST study comparing early heart rhythm to heart rate control showed lower rates of cardiovascular mortality, stroke, and hospitalization, with no increase in complications, for the early control of heart rhythm [6].

Longer intervals between AF onset and interventional treatment are associated with a higher risk of recurrence, for both paroxysmal and persistent AF [7]. Mortality and the risk of stroke are higher in persistent or permanent $\mathrm{AF}$ than in paroxysmal AF [8].

Antiarrhythmic drugs also have a more limited efficacy than ablation for preventing AF recurrence and may be associated with serious side effects. Efficacy is even lower for asymptomatic episodes. Atrial remodeling, as assessed by measurements of atrial strain on echocardiography, worsens in patients on antiarrhythmic drugs, whereas recovers in patients who have undergone ablation [9]. The rate of progression to persistent AF is markedly lower after ablation than with antiarrhythmic drugs, at 2.4 to $2.7 \%$, and it remains stable. With conventional treatment, progression to the persistent $\mathrm{AF}$ is 10 to $20 \%$ after 1 year and reaches 50 to $77 \%$ after 12 years [10]. 
2 Results of the three new studies: EARLY-AF [11], STOP AF First [12], and Cryo-FIRST [13]

\subsection{Recurrences of atrial arrhythmia}

The three new studies demonstrate the superiority of pulmonary vein isolation by cryoablation over antiarrhythmic drugs for preventing recurrences of atrial arrhythmia. The rate of atrial arrhythmia recurrences at 1 year was between 17.8 and $42.9 \%$ for patients treated by cryoablation and 32.4 and $67.8 \%$ for those on antiarrhythmic drugs (Table 1). This difference was statistically significant in the three studies. However, the differences in the results between these three trials, testing the same hypothesis, are striking. The reasons for differences in the rate of symptomatic AF recurrence or AF burden may be due to several points.

First, the types of patients included differed between the studies, in terms of age, exclusion criteria, associated heart disease, and comorbidities. In particular, the patients in the STOP AF First study were older and had a higher frequency of hypertension. Furthermore, this study, unlike Cryo-FIRST, did not exclude patients with a history of coronary artery disease. A considerable number of patients had already undergone electrical or pharmacological cardioversion in EARLY-AF (30 to 40\%) and STOP AF First (25 to $30 \%$ ), suggesting a longer disease duration, than for the Cryo-FIRST study in which cardioversion was an exclusion criterion. CHA2DS2-VASc score for the patients also differed between the three studies, at 1.9 for EARLY-AF, 1.6 for STOP AF First, but only 0.7 for Cryo-FIRST.

The method used for the detection of recurrent atrial arrhythmia also differed between studies. For example, the method used in EARLY-AF, based on the use of an implantable loop recorder, was much more sensitive than the methods used in STOP AF First and Cryo-FIRST. Relative to the use of an implantable loop recorder, the monitoring used in STOP-AF would be expected to have a sensitivity of $40.9 \%$ for the detection of recurrence and that used in Cryo-FIRST, $58.4 \%$ [14]. With a sensitivity of $100 \%$, it is not surprising that the rate of recurrent atrial arrhythmia was highest in EARLY-AF, particularly for asymptomatic episodes. However, within each study, the same monitoring method was used for the two randomized groups, and the relative recurrence rates are therefore comparable. It is notable that the relative benefit of first-line cryoablation was remarkably consistent between the three studies.

Overall, the patients included in Cryo-FIRST were younger and had no underlying heart disease. [15] Recurrence rates were lowest in this population, particularly as ECG monitoring was not rendered continuous using an implantable device.

Table 1 Studies assessing cryoballoon pulmonary vein isolation to antiarrhythmic drugs, in first-line therapy, in patients with symptomatic paroxysmal atrial fibrillation

\begin{tabular}{|c|c|c|c|c|c|}
\hline $\begin{array}{l}\text { Study name } \\
\text { Inclusion criteria }\end{array}$ & Endpoints & & Cryoablation & Antiarrhythmic drugs & $\begin{array}{l}\text { Method used to detect } \\
\text { recurrences }\end{array}$ \\
\hline $\begin{array}{l}\text { EARLY-AF [11] } \\
\text { At least one episode of } \\
\text { symptomatic AF } \\
>18 \text { years old. Author- } \\
\text { ized episodic use of } \\
\text { antiarrhythmic drugs }\end{array}$ & $\begin{array}{l}\text { Recurrence of symp- } \\
\text { tomatic or non- } \\
\text { symptomatic atrial } \\
\text { tachyarrhythmia after } \\
\text { the blanking period }\end{array}$ & $\begin{array}{l}\text { No. of patients } \\
\text { Age (years) } \\
\text { All recurrences } \\
\text { Symptomatic recur- } \\
\text { rences } \\
\text { Cryoballoon procedure } \\
\text { Antiarrhythmic drugs } \\
\text { SAE }\end{array}$ & $\begin{array}{l}154 \\
57.7 \\
42.9 \% \\
11.0 \% \\
100 \% \text { success } \\
- \\
- \\
3.2 \%\end{array}$ & $\begin{array}{l}149 \\
59.5 \\
67.8 \%, p<0.001 \\
26.2 \% \\
- \\
\text { Class Ic: } 81.2 \% \\
\text { Class III: } 18.8 \% \\
4.0 \%\end{array}$ & $\begin{array}{l}\text { Implantable loop recorder } \\
\text { with AF detection } \\
\text { algorithm }\end{array}$ \\
\hline $\begin{array}{l}\text { STOP AF First [12] } \\
\text { Symptomatic AF } \\
\text { episodes } \\
\text { Patients aged } 18 \text { to } \\
80 \text { years with no prior } \\
\text { AA }\end{array}$ & $\begin{array}{l}\text { Recurrent atrial arrhyth- } \\
\text { mia, use of AA in the } \\
\text { cryoballoon arm, abla- } \\
\text { tion after the blanking } \\
\text { period }\end{array}$ & $\begin{array}{l}\text { No. of patients } \\
\text { Age } \\
\text { All recurrences } \\
\text { Cryoballoon procedure } \\
\text { Antiarrhythmic drugs } \\
\text { SAE }\end{array}$ & $\begin{array}{l}104 \\
60.4 \\
25.4 \% \\
97 \% \text { success } \\
- \\
- \\
14 \%\end{array}$ & $\begin{array}{l}99 \\
61.6 \\
55.0 \%, p<0.0001 \\
- \\
\text { Class Ic: } 69 \% \\
\text { Class III: } 21 \% \\
14 \%\end{array}$ & $\begin{array}{l}\text { 24-h Holter monitoring } \\
\text { Trans-Telephonic moni- } \\
\text { toring weekly and in the } \\
\text { event of symptoms }\end{array}$ \\
\hline $\begin{array}{l}\text { Cryo-FIRST [13] } \\
\text { At least } 2 \text { episodes of } \\
\text { symptomatic AF in } \\
\text { the last } 6 \text { months } \\
\text { No prior AA }\end{array}$ & $\begin{array}{l}\text { Atrial arrhythmia for } \\
\text { more than } 30 \mathrm{~s} \text { after } \\
\text { the blanking period }\end{array}$ & $\begin{array}{l}\text { No. of patients } \\
\text { Age } \\
\text { All recurrences } \\
\text { Cryoballoon procedure } \\
\text { Antiarrhythmic drugs } \\
\text { SAE }\end{array}$ & $\begin{array}{l}107 \\
50.5 \\
17.8 \% \\
100 \% \text { success } \\
- \\
- \\
9 \%\end{array}$ & $\begin{array}{l}111 \\
54.0 \\
32.4 \%, p=0.013 \\
- \\
\text { Class Ic: } 92.2 \% \\
\text { Class III: } 7.7 \% \\
4 \%\end{array}$ & $\begin{array}{l}\text { 7-day Holter monitoring } \\
\text { before and at } 1 \text { month } \\
\text { and then every } 3 \text { months } \\
\text { thereafter }\end{array}$ \\
\hline
\end{tabular}

$S A E$ serious adverse event 


\subsection{Symptomatic AF burden}

In EARLY-AF, the AF burden was reduced by $3.3 \pm 1.0 \%$ in the ablation group. The recurrence rate was low if only symptomatic episodes were considered: $11.0 \%$ for cryoablation and $26.2 \%$ for antiarrhythmic drugs. The recorded rates were, however, much higher if the asymptomatic episodes detected with the implantable loop recorder were considered: $42.9 \%$ for cryoablation and $67.8 \%$ for antiarrhythmic drugs. These findings highlight the frequent association of asymptomatic AF with symptomatic AF, both in patients treated with antiarrhythmic agents or undergoing ablations. In both cases, the symptoms may be masked by treatment. It is therefore important to perform close ECG monitoring, to prevent the progression of $\mathrm{AF}$ and the constitution of atrial cardiopathy.

The intensity of ECG monitoring differed between the three studies: full monitoring with an implantable loop recorder in EARLY-AF, a loop recorder and systematic transmission by telephone and during symptoms in STOP AF First, and a loop recorder for 7 days in Cryo-FIRST, before and 1 month after randomization and then every 3 months thereafter. In Cryo-FIRST, data for the percent of time in atrial fibrillation during the 7-day Holter monitoring were therefore available for the baseline and then after randomization. This parameter, which cannot truly be called the AF burden, decreased significantly relative to baseline in the cryoablation arm, and to a lesser extent in the antiarrhythmic drug arm.

\subsection{Quality of life}

Scores were used to assess quality of life in all three studies. The most frequently used score was the AFEQT score, which is a specific score for patients with AF. The evaluation includes symptoms, everyday activities, and anxiety about AF treatment, each of which is scored on a scale of 1 to 7 . Consistent results were obtained in all three trials, with a statistically significant improvement of the AFEQT and EQ5D scores from baseline to 12 months in STOP AF First and EARLY-AF. The magnitude of improvement was clinically meaningful. For example, the incidence rate of patient-reported days with symptomatic palpitations was lower in the cryoballoon group $(P<0.001)$ in Cryo-FIRST, and EARLY-AF reported no symptoms for $85.1 \%$ of patients of the cryoablation group (vs. $73.2 \%, \mathrm{HR}=1.17$ ).

This result is important because it indicates that a greater improvement in quality of life was obtained with first-line ablation, even for patients with symptoms presumed to be recent and not necessarily already disabling.

We observed a trend toward less healthcare utilization with first-line cryoballoon ablation in the three studies, but the differences did not reach significance. In CRYO-FIRST, the annualized rate of hospital or emergency service access due to symptoms caused by atrial arrhythmia recurrence was 0.23 in the cryoballoon and 0.35 in the AAD group (IRR $0.67,95 \%$ CI $0.41-1.10 ; P=0.11)$. In EARLY-AF, emergency department visits were $18.2 \%$ in the ablation group vs. $20.1 \%$ in the antiarrhythmic drug group $(\mathrm{HR}=0.90$ (0.57-1.44)). Similarly, in STOP AF first, the authors found no significant differences at 12 months between the two groups in the percentage of patients free from a cardiovascular healthcare utilization event $(69.9 \%$ in the ablation group and $53.5 \%$ in the antiarrhythmic drug group).

\subsection{Complications}

Severe adverse events occurred with a similar frequency in the two treatment arms. Serious procedural complications were very rare, with no tamponade. This is a key advantage of cryoablation, given the rate of tamponade collected in radiofrequency ablation studies. Only one stroke in each treatment arm was observed for the three studies combined.

\section{Conclusion}

First-line cryoablation is superior to drug therapy in terms of preventing the recurrence of symptomatic episodes, decreasing AF burden, and improving quality of life in symptomatic paroxysmal AF. The rate of serious procedural complications is low. All three studies gave identical results at 1 year of follow-up. A longer period of follow-up will be required to confirm these good results in the long term.

\section{Declarations}

Conflict of interest The authors declare no competing interests.

\section{References}

1. Chugh SS, Roth GA, Gillum RF, Mensah GA. Global burden of atrial fibrillation in developed and developing nations. Glob Heart. 2014;9:113-9.

2. Hindricks G, Potpara T, Dagres N, Arbelo E, Bax JJ, BlomströmLundqvist C, Boriani G, Castella M, Dan GA, Dilaveris PE, Fauchier L, Filippatos G, Kalman JM, La Meir M, Lane DA, Lebeau JP, Lettino M, Lip GYH, Pinto FJ, Thomas GN, Valgimigli M, Van Gelder IC, Van Putte BP, Watkins CL; ESC Scientific Document Group. 2020 ESC Guidelines for the diagnosis and management of atrial fibrillation developed in collaboration with the European Association for Cardio-Thoracic Surgery (EACTS): The Task Force for the diagnosis and management of atrial fibrillation of the European Society of Cardiology (ESC) Developed with the special contribution of the European Heart Rhythm Association (EHRA) of the ESC. Eur Heart J. 2021 Feb 1;42(5):373-498. doi: 
10.1093/eurheartj/ehaa612. Erratum in: Eur Heart J. 2021 Feb 1;42(5):507. Erratum in: Eur Heart J. 2021 Feb 1;42(5):546-547. Erratum in: Eur Heart J. 2021 Oct 21;42(40):4194.

3. Hakalahti A, Biancari F, Nielsen JC, Raatikainen MJ. Radiofrequency ablation vs. antiarrhythmic drug therapy as first line treatment of symptomatic atrial fibrillation: systematic review and meta-analysis. Europace. 2015;17:370-8.

4. Shinagawa K, Shi YF, Tardif JC, Leung TK, Nattel S. Dynamic nature of atrial fibrillation substrate during development and reversal of heart failure in dogs. Circulation. 2002;105:2672-8.

5. Padfield GJ, Steinberg C, Swampillai J, Qian H, Connolly SJ, Dorian P, et al. Progression of paroxysmal to persistent atrial fibrillation: 10-year follow-up in the Canadian Registry of Atrial Fibrillation. Heart Rhythm. 2017;14:801-7.

6. Kirchhof P, Camm AJ, Goette A, Brandes A, Eckardt L, Elvan A, et al. Early rhythm-control therapy in patients with atrial fibrillation. N Engl J Med. 2020;383:1305-16.

7. Chew DS, Black-Maier E, Loring Z, Noseworthy PA, Packer DL, Exner DV, et al. Diagnosis-to-ablation time and recurrence of atrial fibrillation following catheter ablation: a systematic review and meta-analysis of observational studies. Circ Arrhythm Electrophysiol. 2020;13:e008128.

8. Link MS, Giugliano RP, Ruff CT, Scirica BM, Huikuri H, Oto A, Crompton AE, Murphy SA, Lanz H, Mercuri MF, Antman EM, Braunwald E; ENGAGE AF-TIMI 48 Investigators. Stroke and Mortality Risk in Patients With Various Patterns of Atrial Fibrillation: Results From the ENGAGE AF-TIMI 48 Trial (Effective Anticoagulation With Factor Xa Next Generation in Atrial Fibrillation-Thrombolysis in Myocardial Infarction 48). Circ Arrhythm Electrophysiol. 2017 Jan;10(1):e004267. doi: 10.1161/ CIRCEP.116.004267. PMID: 28077507.

9. Walters TE, Nisbet A, Morris GM, Tan G, Mearns M, Teo E, et al. Progression of atrial remodeling in patients with high-burden atrial fibrillation: implications for early ablative intervention. Heart Rhythm. 2016;13:331-9.
10. Proietti R, Hadjis A, AlTurki A, Thanassoulis G, Roux JF, Verma A, et al. A systematic review on the progression of paroxysmal to persistent atrial fibrillation: shedding new light on the effects of catheter ablation. JACC Clin Electrophysiol. 2015;1:105-15.

11. Andrade JG, Wells GA, Deyell MW, Bennett M, Essebag V, Champagne J, et al. EARLY-AF Investigators. Cryoablation or drug therapy for Initial treatment of atrial fibrillation. N Engl J Med. 2021;384(4):305-15. https://doi.org/10.1056/NEJMoa2029 980.

12. Wazni OM, Dandamudi G, Sood N, Hoyt R, Tyler J, Durrani S, et al. STOP AF First trial investigators. Cryoballoon ablation as initial therapy for atrial fibrillation. N Engl J Med. 2021;384(4):316-24.https://doi.org/10.1056/NEJMoa2029554.

13. Kuniss M, Pavlovic N, Velagic V, Hermida JS, Healey S, Arena G, et al. Cryo-FIRST Investigators. Cryoballoon ablation vs. antiarrhythmic drugs: first-line therapy for patients with paroxysmal atrial fibrillation. Europace. 2021;23(7):1033-41.

14. Aguilar M, Macle L, Deyell MW, Yao R, Hawkins NM, Khairy $\mathrm{P}$, Andrade JG. Influence of monitoring strategy on assessment of ablation success and postablation atrial fibrillation burden assessment: implications for practice and clinical trial design. Circulation. 2022;145(1):21-30.

15. Hermida JS, Chen J, Meyer C, Iacopino S, Arena G, Pavlovic N, et al. Cryoballoon catheter ablation versus antiarrhythmic drugs as a first-line therapy for patients with paroxysmal atrial fibrillation: rationale and design of the international Cryo-FIRST study. Am Heart J. 2020;222:64-72.

Publisher's Note Springer Nature remains neutral with regard to jurisdictional claims in published maps and institutional affiliations. 